\title{
GLOBAL AND DOMESTIC BULGARIAN PRODUCTION OF COCOA AND CHOCOLATE ARTICLES FOR THE PERIOD 2013-2016
}

\author{
G. Slavova \\ Department of Economics of Agriculture, University of Economics-Varna, Bulgaria
}

\begin{abstract}
Chocolate is one of the most delicious and popular desserts on earth, but for many people around the world, it is also a serious industry. It is made from cocoa beans that grow on cocoa trees. Historians believe that chocolate consumption dates back before Columbus discovered North America, mainly in Central American societies, where it has been used for more than five millennia. Archaeological excavations prove that in Costa Rica, the Mayans drank cocoa about 400 B.C. Today, however, chocolate production and consumption is a complex commercial task that covers manufacturers and trade networks around the world. The number of cocoa miners in the world is over 14 million people. Almost $35 \%$ of the cocoa beans originate in Côte d'Ivoire. This article aims to analyze the main problems and difficulties in the world's cocoa-producing countries as well as to compare the producers, importers and exporters of cocoa and chocolate products in the European Union, including Bulgaria, by focusing on the change in production and consumption over the last years to highlight main trends and dependencies.
\end{abstract}

Key words: chocolate, cocoa, analyze, cocoa-producing, import, export

Chocolate is one of the most delicious and most popular dessert foods in the world, but for many people on a global scale, chocolate also is a major industry. To support our opinion, we can quote the fact that in 2016, the global chocolate market has reached a value of 98.30 billion USD [1]. Chocolate is produced by cocoa grains, which grow on cocoa trees. Historians think consumption of chocolate dates back to prior the discovery of Northern America by Columbus, mostly in Central American societies, and its use goes back to more than five millennia. Archeological excavations in Costa Rica have proven that Mayans drank cocoa back in 400 BC. In the world of today, however, production and consumption of chocolate is a complex trade issue, involving global trade networks. The number of employees in the cocoa production industry exceeds 14 million people worldwide. The ten largest cocoa production countries in the world are distributed among four continents, all typical for their southern, warm and humid climate, suitable not just for growing cocoa, but also legumes. These countries are situated in Africa, Northern and Southern America, with four of the five major producers situated Africa. Cocoa grains are the main ingredient in the production of chocolate. Western Africa produces approximately two thirds of cocoa grains globally. Almost 35\% of this production of cocoa grains originates from Ivory Coast. According to reports of the World Cocoa Foundation (WCF), approximately 50 million people worldwide are dependent on cocoa production, and the cocoa industry is their main livelihood.

According to the World Food and Agriculture Organization of the United Nations, Table 1 presents the best cocoa producers in the world for 2015, and Figure 1 expresses the dynamics in the quantity of cocoa production, which for the most part is realized in the main cocoa grains production countries.

Figure 1 and Table 1 clearly indicate that Ivory Coast has retained the first place over the full period of examination as a production country, and it has delivered more than 30 percent of the total volume of cocoa globally. The country is a leading producer, overtaking all other countries by more than half a million metric tons, with a total of more than 1448 992 tons produced in 2012 and approximately 1800500 million metric tons produced in 2016. Companies such as Nestle and Cadbury are the recipients of the most of the cocoa originating from Ivory Coast. Two thirds of commercial earnings in this country are based on sales of cocoa to large chocolate production and trade corporations. Despite all of the positive economic trends, the country has a 
major social and humanitarian problem, with children working in cocoa plantations, with some of the children subjected to both 100hours work weeks and physical abuse. Except for the harsh work conditions, child workers in Ivory Coast often do not receive any education whatsoever. Despite spending their whole life growing the world's cocoa supply, some of the farmers in Ivory Coast and some of the children working for these farmers have never even tasted chocolate.

Table 1. Major cocoa producers worldwide for 2015

\begin{tabular}{|l|l|r|}
\hline Rank & Country producer & $\begin{array}{c}\text { Production in tons, million } \\
\text { metric tons }\end{array}$ \\
\hline 1. & Ivory Coast & 1648992 \\
\hline 2. & Ghana & 835466 \\
\hline 3. & Indonesia & 477500 \\
\hline 4. & Nigeria & 367000 \\
\hline 5. & Cameroon & 275000 \\
\hline 6. & Brazil & 256186 \\
\hline 7. & Ecuador & 128446 \\
\hline 8. & Mexico & 82000 \\
\hline 9. & Peru & 71175 \\
\hline 10. & Dominican Republic & 68021 \\
\hline
\end{tabular}

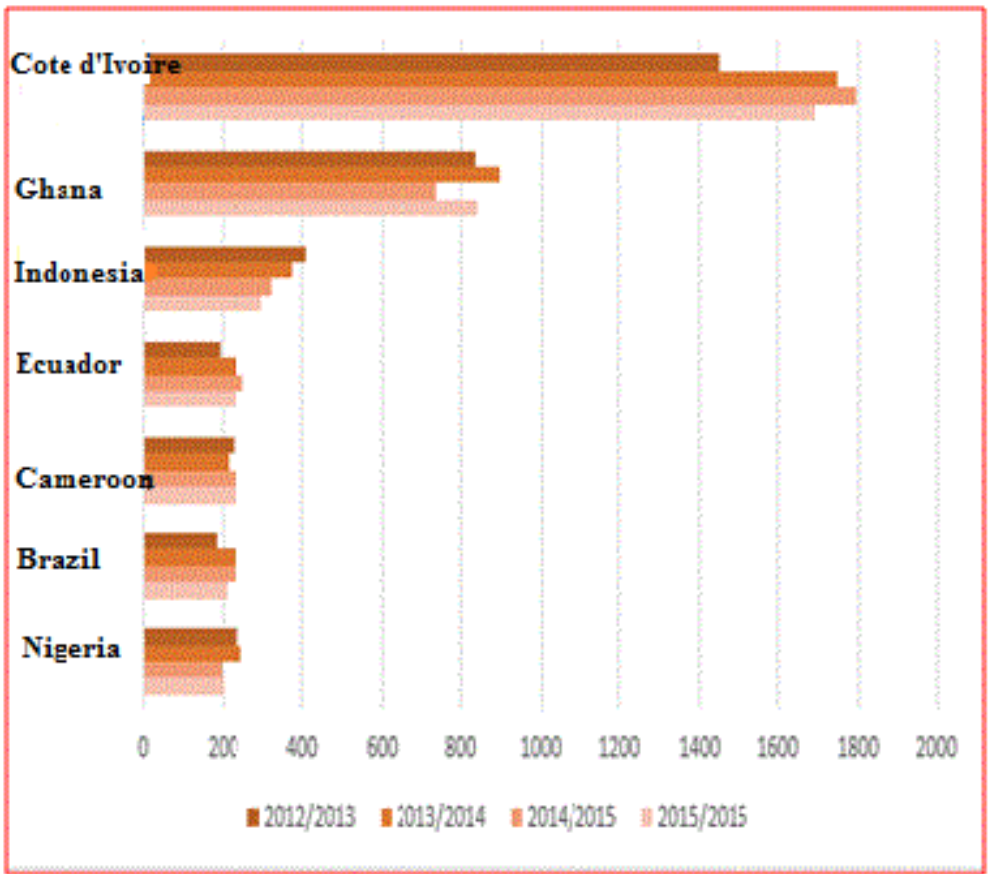

Figure 1. Quantity of cocoa produced globally in million metric tons for the period 2012-2016

Ghana is the second largest country in the world in terms of production of cocoa grains, but what's typical for the country is that some of its agricultural cocoa producers are illegally exporting and selling their cocoa production in Ivory Coast, as the price on Ivory Coast market is $50 \%$ higher. More than three quarters of agricultural producers in the country define themselves as small agricultural producers, and this means that cocoa producers that create and maintain their farms directly, are in fact of cocoa plantation owners.

Most of the cocoa in Indonesia is also produced in small farms, but they are supported by the Institute for Development of
Overseas and Oceanic Agricultural Production. In Indonesia a small share of cocoa production is owned by large multinational chocolate corporations. In Nigeria men and women do not receive equal wage for equal work on the production and collection of, which is a great injustice. Nigeria has increased its cocoa production from 367000 to 421300 tons in 2013-2014. The increase in cocoa prices globally, the increase in demand and the improved accessibility of state-of-the-art agricultural technologies have resulted in significant growth in the cocoa industry in Nigeria, and subsequently - on a global scale. 
Historically, Cameroon has always been one of the greatest cocoa producers globally, but most of the cocoa trees, which are quite old now, must be replaced in their entirety; this has not happened over the last 35 years, however. The sixth largest cocoa producer in the world is Brazil. It is a net importer of cocoa - which means Brazilians consume more cocoa than they export. The Brazilian government has projected for Brazilian production of cocoa to drop another $15.7 \%$ between 2016 and 2024, but Brazil still remains the largest producer of cocoa in the North and South America, with almost 256,186 metric tons of cocoa grains produced in 2013.

The cocoa industry in Ecuador is one of the oldest in the world. It dates back 5000 years. Ecuadorian cocoa is famous for its great quality and it's quite distinctive from cocoa produced in other parts of the world. Because of this, Ecuadorian cocoa is mostly sold not by large corporations, but by small boutique cocoa articles producers based in Belgium, Germany, Luxembourg and Great Britain.

Mexico has always been among the main global cocoa producers, but analysis conducted in recent years has shown one of the main reasons for the decrease in cocoa production in the country is a disease on cocoa plants, which causes cocoa pods to rot. Chocolate giants, being Hershey and Ferrero, have had major investments over the period 2012-2016 in cocoa production plants in Mexico, but despite the large investments in production, Mexican cocoa level has indeed dropped by $50 \%$ compared to the levels at the beginning of 2000. In effect, Mexico has to import more cocoa than it exports.

Peru, other than being cocoa grains producer, is also notorious for being the biggest global producer of cocaine. Cocoa production is the second biggest production in the country. The Dominican Republic has introduced the "Fairtrade Environmentally Certified" production of cocoa for the first time.

A list of some of the main problematic areas in cocoa production follows:

The farmers in Ghana and Ivory Coast, who for the most part create approximately $60 \%$ of the global cocoa crops, continue to use obsolete methods to grow cocoa, and this is also mostly typical for other major cocoa production countries.

Almost all countries which grow cocoa use child labor, and this malpractice is the most prevalent in Ivory Coast. Underpaid workers, sometimes minors, are perfect for collecting raw materials at very low cost, which also formulates a low level of production prime cost, other than the market price of chocolate and chocolate articles, produced from cocoa.

$>$ None of the cocoa production countries have built a facility for production of chocolate and chocolate articles, and most of cocoa raw materials workers have never tasted chocolate. It is our opinion that the main reason thereof is the direct economic and social interest by large chocolate articles production producers.

A bipolar production model exists: on the one hand yield and production of lowbudget cocoa raw materials and resources, and on the other hand - the production of delicious and expensive chocolate products. This defines the great interest in the sector of production of chocolate articles and the high market entry barrier, set by the ten largest chocolate companies (Figure 2), which are operating and represented. The figure below shows net earnings of the companies in 2015, compared to the expenses paid for cocoa raw materials.

$>$ Premium quality cocoa is mostly purchased by boutique producers of cocoa articles from Belgium, Germany, Luxembourg and Great Britain. Large chocolate production corporations use lower quality of produce and the economy of scale that they are able to apply in the production process means they can set market prices low, and consumers are enthusiastic to accepting that.

$>$ Many of the cocoa plants often have diseases, with correct protection and prevention measures not applied. By way of example, one of the leading causes of drop of cocoa production levels in Mexico is caused by cocoa pods rotting. Figure 2 below presents the largest producers and their net earnings from the European and global sales of chocolate and chocolate articles.

The figure below presents the net earnings of the largest global chocolate producers broken down per specific company and country for the year 2015

Figure 2 clearly indicates that the American Corporation MARS is taking leading roles in the ranking among the ten biggest global chocolate production corporations [1], and furthermore it has firmly consolidated its position over the last 5 years, with average net sales of 17.64 billion dollars for the period. The American corporation Mars Inc. is the producer of the renowned chocolate breakfasts and desserts Mars, Twix, Bounty and Snickers, and the M\&M chocolates. Mondelēz 
International Inc. is ranked second in earnings from sales of chocolate articles, with 14.862 billion dollars from the sales of the main brands - Milka, Toblerone, Côté d'Or, Cadbury and Mikado at the start of the reviewed fiveyear period, and at the end of this period, its earnings amount to 16691 billion dollars [2]. The company ranked third is the Swiss company Nestle, which has average net sales earnings for the period to the amount of 11760 billion dollars, by selling its Smarties, Cailler, Kit Kat and Nesquik brands. Nestle and some other chocolate production corporations form the International Association for Production and Sales of Cocoa Articles (WCF). This organization was established back in 2000, with the objective of supporting the solving of issues related to and affecting agricultural cocoa producers. Another of its main objectives is stabilizing the global production of cocoa. Some of the other objectives of the Foundation are increasing cocoa income for agricultural producers, creating environmental protection programs, and fostering the use of sustainable agricultural techniques.

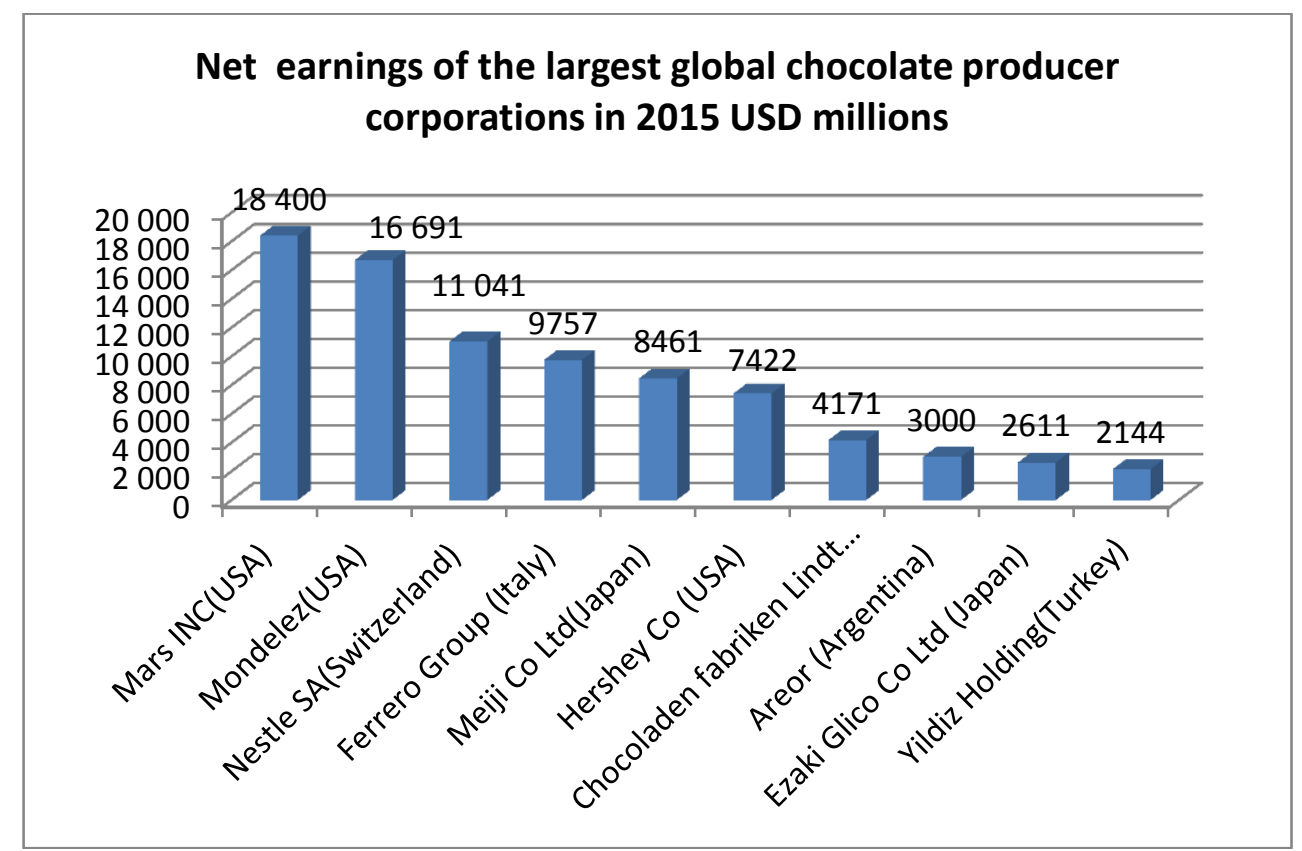

Figure 2. Net earnings of the largest global chocolate producer corporations in 2015

According to a study we have completed we have established that the top four ranked countries in the world producing chocolate are USA, Germany, Switzerland and Belgium. According to global statistical data published in USA, Western Europe has approximately $35 \%$ of the total global chocolate production, and USA has approximately $28 \%$ share [2]. What's interesting is that none of the global largest chocolate production countries is a producer of initial resources - cocoa and no manufacturing facilities for chocolate industrial centers have been developed in the main cocoa producer countries. There is no tangible reason for European countries to be among the leading global producers of chocolate and chocolate articles, other than the popularity of chocolate in Europe, and affection to chocolate after its introduction to the Old Continent. Northern and Southern America have inherited, in our opinion, their addiction to chocolate through European immigrants, and manufacturing companies, such as Mars, Inc. and Hershey Foods
Corporation, which appear to utilize the high demand for this product. USA is one of the best producers of high-quality chocolates in the world, followed by Belgium, Switzerland and Germany. American chocolate producers realize more than 20 billion US dollars per annum in profit from retail sales. The largest chocolate company in North America and one of the most famous chocolate brands globally is the Hershey Foods Corporation, better known as Hershey Co. The company seat is in Hershey, Pennsylvania, and it has been founded back in 1894 by Milton S. Hershey [4].

Most corporations committed to the production of chocolate in USA and in the Western European countries are buying cocoa grains from Ivory Coast in Western Africa. In North America, chocolate stores are mostly concentrated in New York and San Francisco, as well as the largest cities in different states. The reputable global chocolate stores in New 
York are MarieBelle, Li-LAC and Richart Design et Chocolat [3].

German chocolate producers realize profits of almost 10 billion USD per year from this industry. The town of Cologne is considered the chocolate capital of Germany. Chocolate stores in USA import chocolates from the German town to supplement and sell German chocolates alongside the US brands of chocolates. Stollwerck Chocolates Company is one of the most well-known companies, producer of chocolate in the country; the Corporation also has production facilities in Belgium and in Switzerland. Other famous chocolate brands in Germany are La Maison Du Chocolat, Tortchen and Leonidas.

Switzerland is famous for its chocolate delicatessen and the major chocolate production companies. The production of chocolate is one of the main sources of richness for Switzerland. Zurich is often considered as the chocolate production capital in the country. The globally renowned chocolate brands of Swiss origin include Nestle, Toblerone, Lindt and Sprüngli. Chocolate production in Switzerland started back in the $17^{\text {th }}$ century. Since the $19^{\text {th }}$ century to the end of WWII, the Swiss chocolate industry is oriented toward export. Switzerland is the first-ranked country in the world in consuming chocolate produced domestically. In 2000 , approximately $54 \%$ of the chocolate in the country is consumed by Swiss citizens. The chocolate industry in Switzerland in 2005 contributes with 14 billion USD to the produced gross domestic product of the country. Belgium is also a renowned producer of chocolate. A total of 15 chocolate factories have been established in the country and more than 2000 chocolate stores have been opened. One of the globally renowned chocolate companies, Godiva, is based in Brussels. The Belgian chocolatiers generate annual sales of approximately 12 billion USD. Since 1884, the contents of Belgian chocolate have been defined under a law. Predominant share of chocolate companies in Belgium produce chocolate manually, without the support of state-of-the-art equipment, typical for and applied in other developed countries, which produce chocolate articles.

Table 2 below shows chocolate produced in billion tons in EU countries and the number of enterprises in Norway and Germany for the same analyzed period.

Table 2. Produced quantity of chocolate in the European Union and number of companies in Germany and Norway

\begin{tabular}{|c|c|c|c|}
\hline Year & $\begin{array}{l}\text { Produced billion tons of } \\
\text { chocolate articles in EU }\end{array}$ & $\begin{array}{l}\text { Number of } \\
\text { chocolate } \\
\text { companies in } \\
\text { Germany }\end{array}$ & $\begin{array}{c}\text { Number of } \\
\text { chocolate } \\
\text { companies in } \\
\text { Norway }\end{array}$ \\
\hline 2008 & $3,298.43$ & 262 & 28 \\
\hline 2009 & $2,835.07$ & 259 & 25 \\
\hline 2010 & $2,883.87$ & 255 & 33 \\
\hline 2011 & $3,360.13$ & 263 & 36 \\
\hline 2012 & $2,813.24$ & 268 & 38 \\
\hline 2013 & $2,914.73$ & 268 & 41 \\
\hline 2014 & $2,876.47$ & 268 & 36 \\
\hline 2015 & $2,865.45$ & 267 & 38 \\
\hline
\end{tabular}

Germany is the largest European producer of chocolate among EU countries, and for all of Europe, with a total of 917.55 tons of production in 2012 , or a third of the chocolate, produced in Europe. There are more than 265 chocolate production companies in the country, and regardless of the fact that their number is lower than the number of Belgian producers, they do produce larger quantities of chocolate, because the Belgian and Swiss producers are focusing more on the high quality of chocolate articles, and not on their quantity. Table 2 clearly indicates that the Norwegian chocolate and chocolate articles production companies are approximately ten times less than the number of their competitors in Germany. Column two in the Table presents us with statistics of the quantity of chocolate produced in billion tons by the EU. In 2013, the European confectionery industry has reached its highest increase of production by 2.9 billion tons of produced chocolate articles. In the same year, the chocolate production sector makes up 43 percent of the confectionery 
industry in Belgium, and in Germany the chocolate production sector makes up 46 percent of the German confectionery industry.
The two figures below show the biggest cocoa importing and exporting countries in EU for the analyzed period: [1]

\section{Bigest cocoa grains importers to EU in EUR million for 2016}

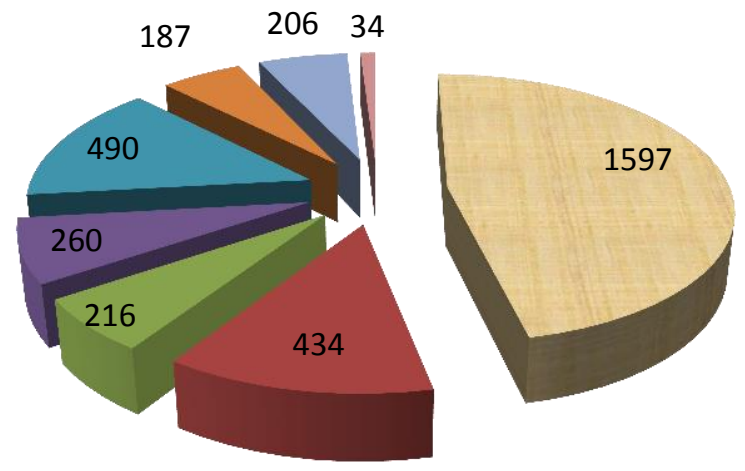

Netherlands
Belgium
Great Britain
France
Germany
Italy
Spain
Others

Figure 3. Largest cocoa grains importer countries to EU in million EUR for 2016

From Figure 3 we can establish that the Netherlands is the country with the highest share of import of cocoa, but this is very natural, because it has the largest European ports, unloading packages from all over the globe, with Belgium, good manual producer of chocolate, ranking second, followed by Germany, one of the largest global producers of chocolate. Figure 4 below presents cocoa exporting countries, and it is easy to establish that the trend indicated for Ivory Coast has preserved in 2016.

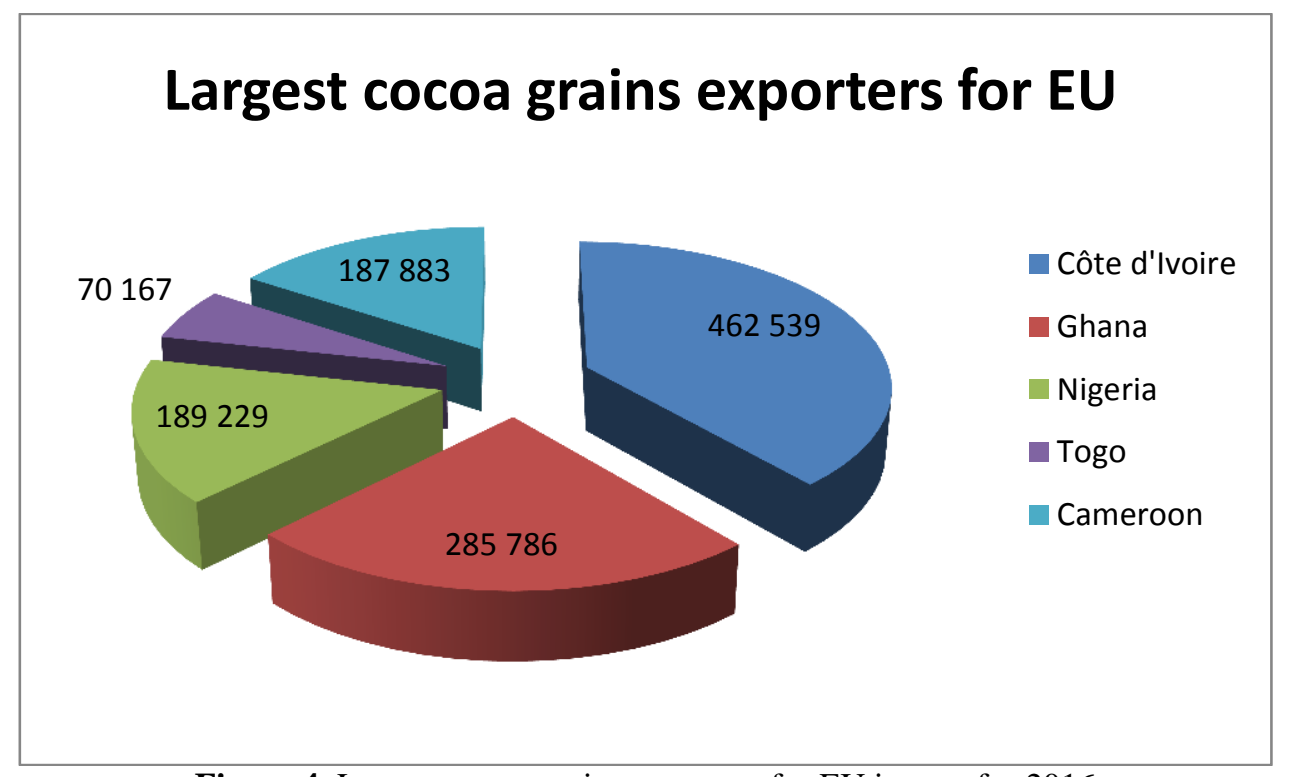

Figure 4. Largest cocoa grains exporters for EU in tons for 2016

Our country is also a big consumer, but also a manufacturer of chocolate articles. The main brands of chocolate articles at the specialized dessert markets are not many. They are "Svoge", "Milka", "Fine Milk Chocolate", "Nestle" and "Lindt". It is an interesting fact that all of the indicated chocolates, with the exception of Lindt and Nestle, have a common production company - Kraft Foods, which in recent years has been renamed Mondelēz Bulgaria. The analyzed chocolate company is in 170 countries, and has more than 100000 employees. One of the latest mergers of the company is in 2010, when Kraft Foods acquired the British company Cudbury, and thus became a leading producer of chocolate and confectionary in the world. The corporation owns 12 product brands, which 
contribute to annual proceeds exceeding 1 billion dollars. Those brands, among others, are Kraft, Jacobs, LU, Cadbury, Milka, Oreo, Oscar Mayer, Philadelphia, etc.

From the economic and social point of view, the purchasing power of the Bulgarian citizen is relatively low compared to the purchasing power of the Western European consumers, and this has forced consumers to focus on the lowest price segment of foods, including the dessert chocolate market. Currently Mondelēz
Bulgaria, which is the inheritor of Kraft Foods offer some of the most accessible prices for maximum quality, and this definitely satisfies the needs of the consumers, who are familiar with their brands (Svoge, Milka and Fine Milk Chocolate), and they favor them. These facts, in our opinion, are the leading factors for the company occupying the leading ranks in the top ten largest producers and traders of chocolate and chocolate articles in the country (Table 3).

Table 3. Largest producers and traders of chocolate and chocolate articles in Bulgaria during the analyzed period

\begin{tabular}{|r|l|r|r|r|}
\hline No. & Production Company & $\begin{array}{r}\text { Production in } \\
\text { kg }\end{array}$ & \multicolumn{1}{|c|}{ Sales in kg } & $\begin{array}{c}\text { Sales with value } \\
\text { in BGN million }\end{array}$ \\
\hline 1. & "Mondelēz Bulgaria" EOOD & 17153416 & 17153416 & 137937 \\
\hline 2. & "Melbon" AD & 1288086 & 1288086 & 7173 \\
\hline 3. & "Interion" AD & 1937755 & 1850144 & 7045 \\
\hline 4. & "Choco Team" OOD & 2586920 & 2313324 & 6455 \\
\hline 5. & "Nestle Bulgaria" AD & 425485 & 402284 & 5185 \\
\hline 6. & "Pobeda" AD & 382449 & 380987 & 4416 \\
\hline 7. & "Vale 1" OOD & 1491184 & 1491184 & 3797 \\
\hline 8. & "Milmex" OOD & 214848 & 214848 & 3085 \\
\hline 9. & "Animeks 98” EOOD & 335037 & 334946 & 1848 \\
\hline 10. & "Midist" EOOD & 229409 & 206866 & 1376 \\
\hline
\end{tabular}

Source: "Capital" newspaper, 2017

In Bulgaria in 2014, approximately 185.4 million BGN of income are realized from the sales of more than 28 thousand tons of chocolate articles. This includes chocolate blocks, chocolate bars, chocolate breakfasts and waffles with added flavors and fills, such as cereals, fruits and nuts. This includes the sale of white chocolate, chocolate figures (eggs, teddy bears, bunny rabbits and other holiday items), chocolates, cocoa cakes, chocolate spread, etc. The main quantities of chocolate sold in the segment are allocated among the chocolate blocks categories (chocolates), with a share of approximately $52 \%$ of the common sales and chocolates with a $31 \%$ share, followed by the group of chocolate spread - approximately $8 \%$. Overall, the business of the top ten company sellers in the segment (exceeding 175 million BGN) concentrates approximately $94.6 \%$ of the value of the local Bulgarian chocolate market (5).

"Mondelēz Bulgaria" EOOD, being the former "Kraft Foods Bulgaria", which only recently changed its name to "Mondelēz Bulgaria", is the company with a strong and leading positions for our country, and it has retained its position as a leader in the production of chocolate articles, biscuits and coffee drinks in our country. The company continues to produce the brands beloved by consumers - Milka, Svoge, Suchard, Toblerone, Oreo, Moreni, BelVita, Tuc, Barni, Jacobs, and New Brazil. The change in the company name is part of the process of international restructuring of "Kraft Foods" and the division of business into two separate companies - "Mondelēz International", committed to the production and retail of chocolates, biscuits, snacks and drinks on a global level, and "Kraft Foods Group", focused on the foodstuffs business in North America. "Mondelēz International" is the biggest producer of chocolates, biscuits and snacks in the world [4], and the second biggest producer of coffee and chewing gums. The change of the corporation is performed on a stage-bystage basis in 165 countries with representative offices of "Mondelēz International". The Bulgarian branch is part of the structure of "Mondelēz" for Central Europe, together with 17 other countries in the region. In Bulgaria the company has two production enterprises in Svoge and in Kostinbrod. The name "Mondelēz" has been selected as a combination of the words "color" and "tasty", and it represents the main objective of the company - to create joy by creating more moments of deliciousness in everyday life. In terms of value, the company turnovers in the chocolate segment (with almost 134.3 million BGN exceed by approximately 3.5 times the 
total income from sales of chocolate articles from the remaining nine companies, presented in Table ..... Most of the production of the company is held by the chocolate blocks category (almost $80 \%$ ) with local brands, such as "Svoge", "Mlechen", LZ, etc. The remaining part of the product list in the segment is formed by the Suchard and "Svoge Seasons" chocolates, with several assortment lines each. The total production volume of the company in last year amounts to a total of more than 17 thousand tons of chocolate articles. Over the last three years, more than 50 million BGN have been invested in the "Mondelēz" chocolate factory in Svoge with a specific objective to retain its product list ranked first in the chocolate market segment. From the Table presented, we can establish that four companies with average turnover ranging between 5 and 10 million BGN are ranked second to firth. These are "Melbon", "Interion", "Choco Team" and "Nestle". The joint-stock companies "Melbon" [5] and "Interion" [6] have similar turnovers - a little more than 7 million BGN. "Interion" $\mathrm{AD}$ produces a large variety of hazelnut, cocoa and white creams with the commercial brand NuCrema, which is very well established on the Greek market. The chocolate company "Choco Team" has focused mainly on the production of chocolate spread and processing of cocoa and cocoa products for the confectionery industry. It also successfully develops waffle products on the market, with the brand "Focus".

"Nestle Bulgaria" has developed a wide range of chocolate articles on the market with a production in the company factory in the city of Sofia. Renowned brands of the company are the chocolates "Kuma Lisa", chocolates with the "Nestle" "Taralezhki" and "Prostor" brands, with rich series of flavors. Five of the ten leading companies have sales turnovers below 5 million BGN. These are: the Burgas factory "Pobeda" AD [7] - with a turnover of 4.42 million BGN, known with the chocolates with the brands "Chernomorets" and "Krem". The Plovdiv factory "Vale 1" OOD (3.8 million BGN) is ranked seventh and its focus is mostly on the production of chocolate spread. "Milmex" OOD (3.1 million BGN), with seat in the city of Sofia, has developed an assortment in the category of chocolates (Delizia, "Sinemorets", "Morsko Dano", etc.), as well as in the luxurious segment of the manually crafted chocolate articles. Ranked nine and ten, with annual sales turnover below 2 million BGN, are the two Sofia factories "Animeks 98" EOOD (chocolates DiVa,
Moccafe, Cherry Love, Mousse, etc.), and "Midist" EOOD, with its main brand being "For You" for chocolate blocks, biscuits, waffles, etc.

\section{CONCLUSION}

The major producers of cocoa crops and raw materials globally over the full period of analysis are Ivory Coast, Ghana, Nigeria and Indonesia, and they retain their global top ranking both as producers and exporters, and Indonesia is even overtaking Nigeria in terms of production, whereas Nigeria is the bigger exporter.

The biggest producers of cocoa grains are the Netherlands and Belgium, but the largest producers of chocolate and chocolate articles globally are USA, Germany, Switzerland and Belgium, and this means that cocoa raw materials imported from the Netherlands are mostly allocated to Germany, Switzerland and Italy, the latter being the next in line major chocolate producer, ranked after the Netherlands and Belgium.

"Mondelēz Bulgaria" is the chocolate company ranked first in our country in terms of production and sales turnover for chocolate articles, and the second largest company on a global scale, and this indicates that our country is not only in line with the global trends in the production and realization of chocolate, but is also an active participant in these trends. A series of domestic companies producing chocolate manually do exist in parallel, similar to the Belgian boutique chocolate, but factory production of chocolate is prevailing.

\section{REFERENCES}

1. Brenner, J., G., The emperors of chocolate: Inside the Secret world of Hershey and Mars", Jan 4, 2000

2. Rohan, M. Global Chocolate, Cocoa Beans, Lecithin, Sugar and Vanilla Market By Market Share, Trade, Prices, Geography Trend and Forecast (2011-2016), 2017,http://www.marketsandmarkets.com

3. Statista- Find statistics, consumer survey results and industry studies from over 18000 sources on over 60000 topics on the internet's leading statistics database https://www.statista.com/, 2017

4. Cormier, Robert, The chocolate war, 2004

5. Official website of a chocolate production company - Melbon, http://www.melbon.euJune 2017

6. Chocolate business in Bulgaria concentrated in ten companies, http://www.capital.bg/specialni_izdaniia/December 2015

7. https://www.pobeda.bg/bg/- Official website of the chocolate production company "Pobeda", Burgas, June 2017 